\title{
Post Service Strength Properties at Elevated TEMPERATURE OF STEEL 14MOV6-3
}

\author{
Damir Hodzic, Adi Pandzic
}
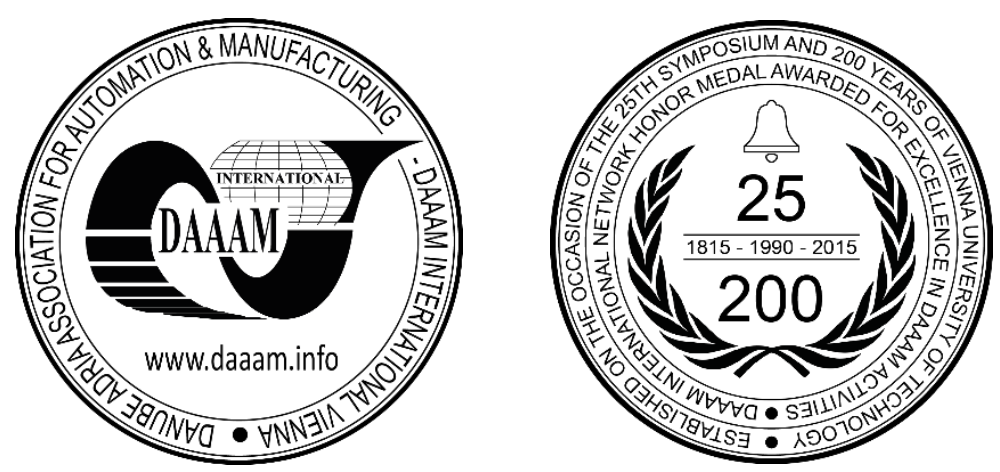

This Publication has to be referred as: Hodzic, D[amir] \& Pandzic, A[di] (2018). Post Service Strength Properties at Elevated Temperature of Steel 14Mov6-3, Proceedings of the 29th DAAAM International Symposium, pp.0384-0387, B. Katalinic (Ed.), Published by DAAAM International, ISBN 978-3-902734-20-4, ISSN 1726-9679, Vienna, Austria DOI: $10.2507 / 29$ th.daaam.proceedings.055

\begin{abstract}
Reliability and safety of thermal power plant components are issues that have become much more important in recent years, so the assessment of damage and of the risk associated with failure have become increasingly important. Records of operating conditions and preventive maintenance for a component that has failed, and for the system as a whole, are relatively good sources of background information. Direct post service evaluation represents an improvement over history-based methods, because no assumptions regarding material properties and past history are made. In order to investigate decrease of strength properties at elevated temperature after prolonged service, low-alloyed steel 14MoV6-3 exposed 194.207 hours to service conditions, has been compared with same, but virgin material. In addition to the standard strain rate test, tensile testing at elevated temperature $540{ }^{\circ} \mathrm{C}$ with high strain rate and slow strain rate is also performed. As a result of prolonged lifetime of exploited material in service there is a significant degradation of strength properties.
\end{abstract}

Keywords: strength; slow strain rate; elevated temperature; post service

\section{Introduction}

Boilers and other types of steam power plant equipment are subjected to a wide variety of failures involving one or more of several mechanisms. Most steam-generator failures occur in pressurized components, that is, the tubing, piping, and pressure vessels that constitute the steam-generating portion of system. Power plants, which were originally intended to provide the base load, are frequently shut down and powered up. Variations in the steam temperature accompanying the power changes induce thermo-mechanical stresses in components, which lead to material degradation and consequently can cause failure [1]. Progressive damage of high-temperature components under service conditions leads to exhaustion of life, thus leading to failure. It should be mentioned that a large number of failures in engineering components occur due to preexisting defects, nonmetallic inclusions or other imperfections (casting, welding defects, etc.), [2]. Nevertheless to the very long history of low-alloyed steel 14MoV6-3, this material is still built in the numerous power plants, particularly in the boilers and its belonging high-temperature components. According to the German Codes VGB-R 509L and TRD 508 the start or extended material inspection is required after about 70.000 hours for steel 14MoV6-3 and about 100.000 hours of exploitation for the other heat resistant steels, [3]. 
Aim of investigation that is presented in this paper is to evaluate degradation of strength properties at elevated temperature of steel 14MoV6-3. It should be emphasized that direct examinations are expensive and time consuming, especially in the case of creep strength testing. For that reason, slow strain rate test was accomplished instead of creep test. Purpose of this test was to evaluate time dependent strength properties degradation and to investigate is it possible to use slow strain rate test as a indicator for creep properties degradation.

\section{Heat resistant boiler steel $14 \mathrm{MoV6}$-3}

The effort to extend designed lifetime of industrial plants operating for a long time at elevated temperatures requires the knowledge of residual lifetime of the critical components. Residual lifetime assessment is unthinkable without the knowledge of mechanical properties of materials prior to operation and mechanical properties after actual time of operation (actual mechanical properties), because the material properties can be reduced throughout the service life, [4]. The steel 14MoV6-3 concept goes back to the dawn of creep resistant steels. Creep rupture strength of steel 14MoV6-3 was clearly superior to that of the higher alloyed steel 10CrMoV9-10 which was adopted in West Germany. The steel 14MoV6-3 is the exception among the creep resistant, weldable, ferritic boiler and pipe steels, since it is hardening, thus differing substantially from the performance of the other creep resistant, ferritic steels.

In order to investigate decrease of mechanical properties of material, low-alloyed steel 14MoV6-3 exposed 194.207 hours of exploitation, has been compared with same, but virgin material. The low-alloyed steel was chosen for this investigation, because it is widely used for steamlines in power plants in Bosnia and Herzegovina, and also because it has been used for long service period (from the year 1968), so that significant decrease of structure and properties can be expected. Investigated material is taken from the Unit 5 main steamline $(\varnothing 245 \times 28 \mathrm{~mm})$ that operated at temperature $540{ }^{\circ} \mathrm{C}$ and pressure $13,5 \mathrm{MPa}$, in thermal power plant TE Kakanj, Bosnia and Herzegovina. Sample of steamline exploited material 14MoV6-3 was cut because of residual life estimation. Virgin material was also cut from the unexploited steamline material 14MoV6-3 $(\varnothing 245 \times 28 \mathrm{~mm})$.

\section{Chemical composition and microstructure}

Chemical composition of investigated material 14MoV6-3 (virgin and exploited) was accomplished in order to confirm that all delivered specimens of steamline are made from the same material, so the results of predicted investigation on virgin and exploited material could be comparable. Method for determination of chemical composition was spectral analysis. Chemical compositions of virgin and exploited steel 14MoV6-3 are presented in Table 1.

\begin{tabular}{|c|c|c|c|c|c|c|c|c|}
\hline 14MoV6-3 & C, \% & Si, \% & Mn, \% & P, \% & S, \% & Cr, \% & Mo, \% & V, \% \\
\hline Virgin & 0,149 & 0,30 & 0,57 & 0,013 & 0,015 & 0,59 & 0,475 & 0,28 \\
\hline Exploited & 0,139 & 0,32 & 0,56 & 0,013 & 0,013 & 0,50 & 0,47 & 0,28 \\
\hline
\end{tabular}

Table 1. Chemical compositions of virgin and exploited steel 14MoV6-3

From the results of chemical composition analysis it was obvious that investigated steamline specimens (virgin and exploited) are made of the same material 14MoV6-3. Slightly less content of Molybdenum, comparing with chemical composition according to DIN 17175, is probably error of measuring without influence on further investigation, because content of Molybdenum is almost the same for virgin and exploited steamline material. In order to investigate microstructure of exploited steamline material, metallographic testing was accomplished. This was done in laboratory at IWS Institute TU Graz, Austria, by testing and comparison of microstructure of virgin material and exploited material. Microstructure of investigated steel $14 \mathrm{MoV} 6-3$ at transversal cross section of steamline pipe with magnification $200 \times$ is shown in Fig. 1, [5].
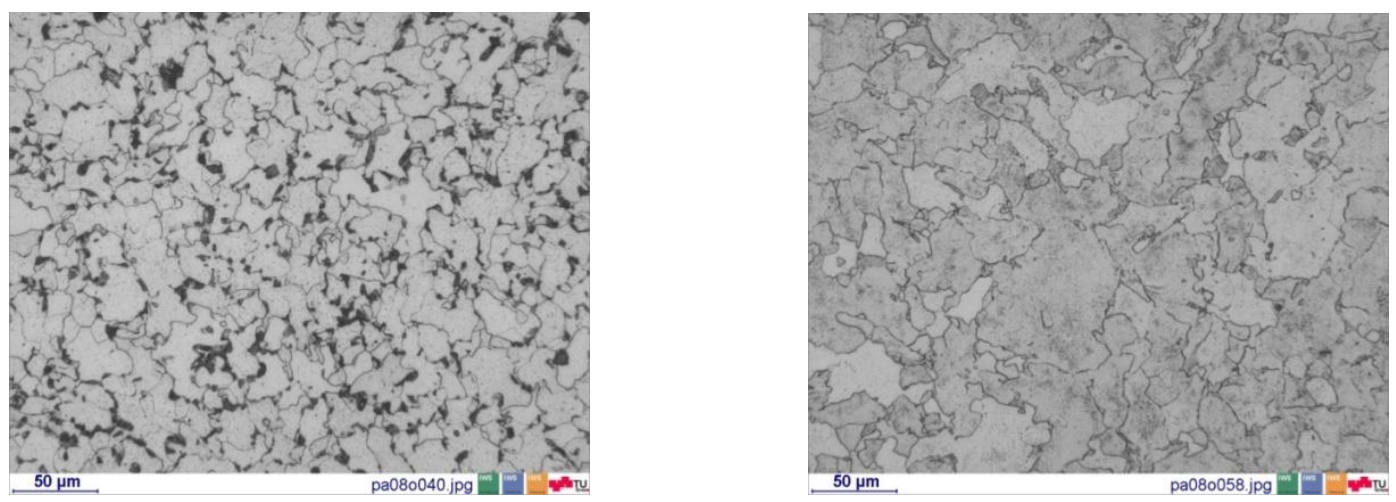

Fig. 1. Microstructure of virgin and exploited steel 14MoV6-3 
Initial microstructure of the 14MoV6-3 low-alloyed steel features the mixture of bainite with ferrite, sometimes with a small amount of pearlite and significant amount of the $\mathrm{M}_{3} \mathrm{C}$ carbides and numerous, very fine $\mathrm{MC}$ type ones. The final structure image after long-term exploitation under service conditions is ferrite with rather homogeneously distributed precipitations inside grains and chains of the significant amount of precipitations on their boundaries, [6]. This microstructure evolution indicates significant decrease of mechanical properties, such as a strength and toughness. It is important to emphasize that metallographic examinations of various steel grades after long-term service at elevated temperature revealed that transformations of carbides and morphological changes of phases have the most significant effect on service properties degradation, [7].

\section{Strength properties at elevated temperature}

Slow strain rate test (SSRT) represent a dynamic slowly increasing strain imposed by an external means on uniaxial tension specimen according to ASTM G 129 standard. It is used for relatively rapid screening or comparative evaluation of environmental, processing or metallurgical variables that can affect resistance of material, [8]. Testing was done for two different slow strain rates $(0,0001 \mathrm{~mm} / \mathrm{s}$ and $0,000254 \mathrm{~mm} / \mathrm{s})$ with tensile testing machine ZWICK ROELL at IWS Institute TU Graz, Austria. Software for data acquisition was testXpert x2.02.0 ZWICK/ROELL. Number of specimens for testing was one per strain rate and specimens with round cross sections for elevated temperature tensile testing were used. Fig. 2 shows equipment used for slow strain rate test and tensile test at elevated temperature.
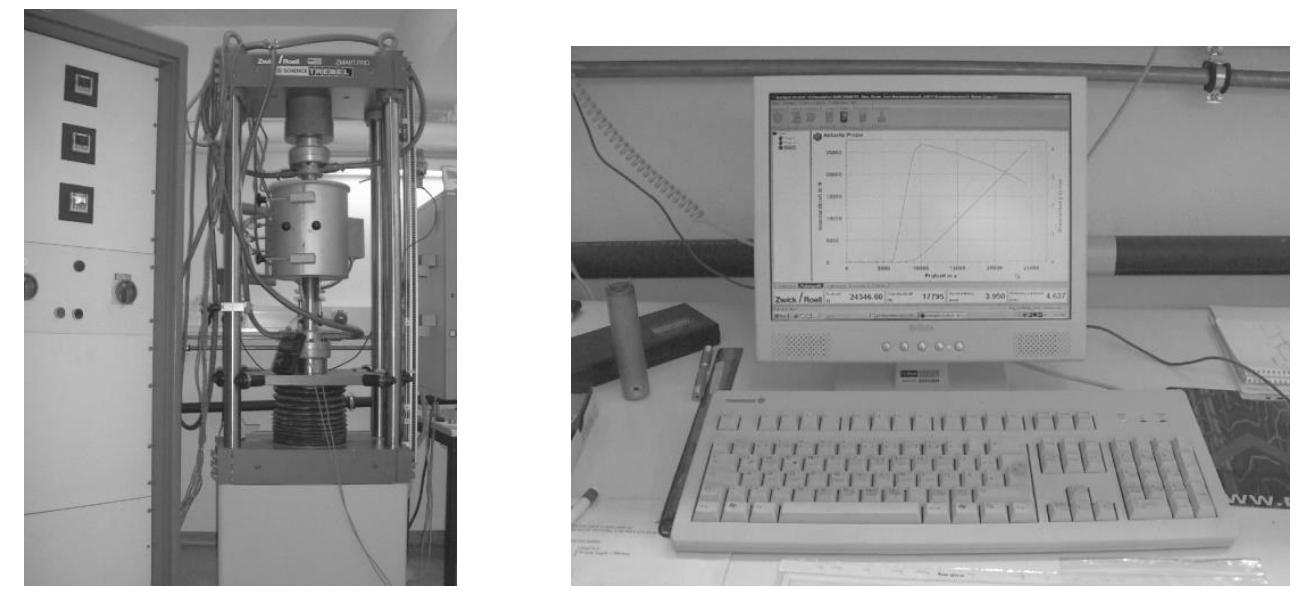

Fig. 2. Testing machine and data acquisition

In addition to the slow strain rate test, tensile testing at elevated temperature $540{ }^{\circ} \mathrm{C}$ with high strain rate $1 \mathrm{~mm} / \mathrm{s}$ and standard strain rate $5 \mathrm{~mm} / \mathrm{min}(0,083 \mathrm{~mm} / \mathrm{s})$ for tensile testing is also performed with the aim to investigate dependence between strain rate and mechanical properties (tensile strength) of steel 14MoV6-3. Results of this investigation are given in comparative manner between virgin and exploited steel 14MoV6-3, as shown in Fig. 3.

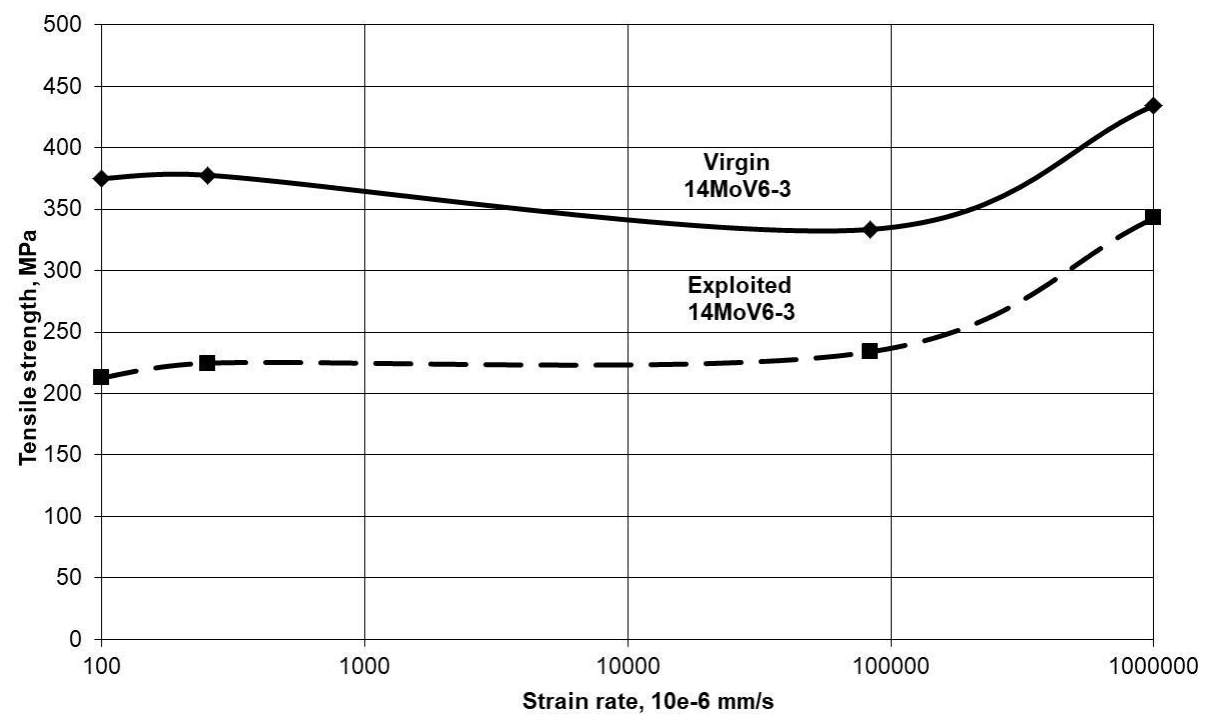

Fig. 3. Strain rate and tensile strength at elevated temperature $540{ }^{\circ} \mathrm{C}$ 
Number of testing specimens was one specimen per strain rate and testing was accomplished with the same equipment that was used for slow strain rate test at elevated temperature $540{ }^{\circ} \mathrm{C}$. Testing time to specimens failure for slow strain rate $0,0001 \mathrm{~mm} / \mathrm{s}$ was approximately 24 hours and for slow strain rate $0,000254 \mathrm{~mm} / \mathrm{s}$ it was approximately 10 hours.

\section{Conclusion}

Progressive degradation of high-temperature components under operating conditions leads to exhaustion of service life, thus leading to failure. Degradation may be defined as a progressive and cumulative change acting to decrease the structural performance of the components that make up the plant. Service life may be defined as the period during which a component can perform its intended function safely, reliably, and economically.

Microstructure changes under the influence of temperature, stress and environment in exploitation cause the substantial degradation of mechanical properties. In the case of the investigated steel 14MoV6-3 microstructure evolution indicates significant decrease of strength properties, that has to be proved by strength testing.

Considering the presented results of strength properties at elevated temperature of steel 14MoV6-3, as a result of prolonged lifetime in service there is a notable degradation of mechanical properties. Through the testing with different strain rates at elevated temperature $540{ }^{\circ} \mathrm{C}$ there is obviously significant decrease of tensile strength and implicitly other strength properties of exploited steel 14MoV6-3 comparing with virgin 14MoV6-3.

It should be noticed that with decreasing of strain rate there is also slightly greater decrease of tensile strength of exploited material comparing with virgin. Implicitly, it means that it could be expected significant decrease of time dependent strength properties like creep rupture strength, but it should be proved by creep testing.

Time dependent deformation and fracture of structural materials at elevated temperatures are among the most challenging engineering problems faced by materials engineers. Creep rupture strength test is extremelly time consuming, even accelerated creep test can last few hundreds or thousands hours and it includes result extrapolation.

In the future, slow strain rate test could be used as a important indicator for evaluation of strength properties degradation trend, especially at elevated temperature, and making decision about post service creep test which is more time consuming and more expensive. At the same time, we should never forget that testing conditions for slow strain rate test and creep rupture strength test are not the same and results are not comparable.

\section{Acknowledgement}

This investigation was partly supported by IWS Institute at Technical University Graz and OEAD Austrian Agency for International Cooperation in Education and Research.

\section{References}

[1] Linn, S. \& Scholz A. (2013). Creep-fatigue Lifetime Assessment with Phenomological and Constitutive Material Laws. Procedia Engineering (6th International Conference on Creep, Fatigue and Creep-Fatigue Interaction CF-6), Vol. 55, 2013, pp. 607-611, ISSN1877-7058, DOI 10.106/j.proeng.2013.03.302

[2] Brnic J. \& Brcic M. (2015). Comparison of Mechanical Properties and Resistance to Creep of 20MnCr5 Steel and X10CrAlSi25. Procedia Engineering (25th DAAAM International Symposium on Intelligent Manufacturing and Automation, 2014), Vol. 100, 2015, pp. 84-89, ISSN1877-7058, DOI 10.106/j.proeng.2015.01.345

[3] ECCC Recommendations - Volume 9, Part II: High Temperature Component Analysis Overview of Assessment \& Design Procedures, ECCC European Creep Collaborative Committee, 2005

[4] Matocha K. (2014). The Use of Small Punch Test for Determination of Fracture Behaviour of Ferritic Steels. Procedia Engineering (1st International Conference on Structural Integrity ICONS-2014), Vol. 86, 2014, pp. 885891, ISSN1877-7058, DOI 10.106/j.proeng.2014.11.110

[5] Hodzic D. \& Hajro I. (2012). Microstructure Degradation after Prolonged Exploitation of Heat Resistant Steel 14MoV6-3. Proceedings of 16th International Research/Expert Conference "Trends in the Development of Machinery and Associated Technology", 10-12 September 2012, Dubai UAE, ISSN 1840-4944, Ekinović S., Yalcin S., Calvet J.V. (Ed.), pp. 155-158, Faculty of Mechanical Engineering in Zenica, Zenica

[6] Hodzic D. \& Hajro I. (2016). Impact Crack Initiation and Propagation Energy of Prolonged Exploited Heat Resistant Steel. Proceedings of the 27th DAAAM International Symposium, pp.0308-0311, B. Katalinic (Ed.), Published by DAAAM International, ISBN 978-3-902734-08-2, ISSSN 1726-6979, Vienna, Austria, DOI: 10.2507/27th.daaam.proceedings.045

[7] Dobrzanski J.; Zielinski A. \& Krtzon H. (2007). Mechanical Properties and Structure of the Cr-Mo-V Low-alloyed Steel after Long-term Service in Creep Condition. Journal of Achievements in Materials and Manufacturing Engineering, Vol. 23, No. 1, (July 2007) page numbers (39-42), ISSN 1734-8412

[8] Standard ASTM G 129-00: Standard Practice for Slow Strain Rate Testing to Evaluate the Susceptibility of Metallic Materials to Environmentally Assisted Cracking, ASTM, 2000 